\title{
Study of the Intelligent Control and Modes of the Arctic-Adopted Wind-Diesel Hybrid System
}

\author{
Viktor Elistratov ${ }^{1}$, Mikhail Konishchev ${ }^{1}$, Roman Denisov ${ }^{1}$, Inna Bogun ${ }^{1, *}$, Aki Grönman ${ }^{2}$, \\ Teemu Turunen-Saaresti ${ }^{2}$ and Afonso Julian Lugo ${ }^{2}$ \\ 1 Higher School of Hydraulic and Power Engineering Construction, Peter the Great St. Petersburg Polytechnic \\ University (SPbPU), Polytechnicheskaya, 29, 195251 St. Petersburg, Russia; elistratov@spbstu.ru (V.E.); \\ mak@vtr-engineering.ru (M.K.); denisov_rs@spbstu.ru (R.D.) \\ 2 School of Energy Systems, LUT University, FI-53851 Lappeenranta, Finland; aki.gronman@lut.fi (A.G.); \\ teemu.turunen-saaresti@lut.fi (T.T.-S.); lugoafonso@gmail.com (A.J.L.) \\ * Correspondence: bogun_iv@spbstu.ru
}

check for updates

Citation: Elistratov, V.; Konishchev, M.; Denisov, R.; Bogun, I.; Grönman, A.; Turunen-Saaresti, T.; Lugo, A.J. Study of the Intelligent Control and Modes of the Arctic-Adopted Wind-Diesel Hybrid System. Energies 2021, 14, 4188. https://doi.org/ $10.3390 /$ en14144188

Academic Editor: Rafael

Sebastián Fernández

Received: 1 May 2021

Accepted: 7 July 2021

Published: 11 July 2021

Publisher's Note: MDPI stays neutral with regard to jurisdictional claims in published maps and institutional affiliations.

Copyright: (c) 2021 by the authors. Licensee MDPI, Basel, Switzerland. This article is an open access article distributed under the terms and conditions of the Creative Commons Attribution (CC BY) license (https:// creativecommons.org/licenses/by/ $4.0 /)$.

\begin{abstract}
For energy supply in the Arctic regions, hybrid systems should be designed and equipped to ensure a high level of renewable energy penetration. Energy systems located in remote Arctic areas may experience many peculiar challenges, for example, due to the limited transport options throughout the year and the lack of qualified on-site maintenance specialists. Reliable operation of such systems in harsh climatic conditions requires not only a standard control system but also an advanced system based on predictions concerning weather, wind, and ice accretion on the blades. To satisfy these requirements, the current work presents an advanced intelligent automatic control system. In the developed control system, the transformation, control, and distribution of energy are based on dynamic power redistribution, dynamic control of dump loads, and a bi-directional current transducer. The article shows the architecture of the advanced control system, presents the results of field studies under the standard control approach, and models the performance of the system under different operating modes. Additionally, the effect of using turbine control to reduce the effects of icing is examined. It is shown that the advanced control approach can reduce fuel consumption in field tests by $22 \%$. Moreover, the proposed turbine control scheme has the potential to reduce icing effects by $2 \%$ to $5 \%$.
\end{abstract}

Keywords: wind energy; hybrid systems; harsh climatic; pitch-control; intelligent control system; icing prediction; predictive analytics; adapted technologies

\section{Introduction}

Most of the Russian and Finnish territories are located in a cold climate. Almost the entire northern part of these countries, as well as Central Siberia and Yakutia in Russia, fall within the cold polar zone of the Arctic, a zone of extremely low temperatures. In these areas, the duration of winter significantly exceeds that of summer with temperatures dipping close to $-50^{\circ} \mathrm{C}$. Conditions here are unique, yet approximately 2.5 million people live in these areas. This is more than the total number of people residing in the Arctic areas of the seven other Arctic nations, all of which have less severe climatic conditions [1].

A significant part of the Arctic territory belongs to the decentralized energy supply zone. This zone is characterized by weak infrastructure associated with its remoteness from regional centers, and electricity is mainly produced by diesel power plants operating on expensive imported fuel. In the Russian areas of this zone, there are approximately 900 diesel power plants in operation, which produce an energy output of about 3.0 billion $\mathrm{kWh}$ annually [1]. The main challenges of supplying power to isolated consumers are the high logistical costs associated with the delivery of fuel and equipment for diesel power plants, the limited transport infrastructure, and, consequently, the high cost of fuel. Additionally, the operating costs of diesel power plants and specific fuel consumption are 
high, and there is typically no monitoring or control automation. As a result, the levelized cost of electricity (LCOE) at diesel power plants in the Arctic regions is $0.25-2.0$ Euro/ $\mathrm{kWh}$, which is much more expensive than in the centralized energy supply zones. To illustrate, the International Energy Agency estimates LCOE values of below 0.1 Euro $/ \mathrm{kWh}$ in Europe for coal, gas, and nuclear energy [2]. In addition, significant damage to the vulnerable natural environment of the Arctic is being caused by the emissions from fuel combustion products ( 40 million tons of carbon dioxide $\left(\mathrm{CO}_{2}\right), 80$ thousand tons of sulfur oxides $\left(\mathrm{SO}_{\mathrm{x}}\right)$, 600 thousand tons of nitrogen oxides $\left(\mathrm{NO}_{\mathrm{x}}\right)$ annually), as well as by the storage of fuel barrels [3].

The Far North and the Arctic regions are characterized by high wind energy potential. In general, Russian and Finnish technical wind energy resources are $10^{16} \mathrm{kWh} /$ year, about $16 \%$ of which are concentrated in the European and Asian northern coastal zones, creating a solid foundation for their effective use [4]. Given this high wind energy potential, optimization and modernization of existing power supply systems and the construction of new ones can be effectively carried out based on modular wind-diesel-storage hybrid systems adapted to Arctic conditions. These systems offer a good opportunity to overcome the challenges related to the intermittent and fluctuating nature of wind energy production, and they can also reduce the use of fossil fuels in distributed energy generation [5,6]. The application of wind-diesel hybrid systems will reduce the use of diesel fuel by $10-60 \%$ and increase the standard service life of diesel generator sets by two to three times [7-10]. In terms of $\mathrm{CO}_{2}$ emissions, a study by Kazem et al. predicts an over $20 \%$ reduction in emissions when using a hybrid wind turbine-diesel engine system as compared with a diesel-only system [3]. It is worth mentioning that, in addition to the time-shifting role of the batteries in these systems, they can also improve the reliability and power quality as highlighted, for example, by Ansari and Velusami [11].

However, one of the key challenges to the optimal operation of Arctic wind turbines is icing. The impact of icing on wind turbine performance can be significant during the cold winter months. Turkia et al. [11] predict an approximately $17 \%$ reduction in turbine performance below nominal power due to icing, and Wei et al. [12] report power generation losses as high as $30 \%$. Different passive and active anti-icing systems have been considered to reduce these effects, including special coatings, black paint, and heating [12]. One option that has not received much interest is airfoil pitch control. Nonetheless, several studies have shown that the optimal airfoil angle of attack can be affected by icing, for example, $[13,14]$, introducing the potential to control the pitch differently during normal and icing operation modes.

Proportional integral (PI) control has traditionally been used in hybrid energy systems $[9,15]$, but it poses problems regarding frequency regulation [11]. Increasing system stability has also been investigated recently [16]. The existing options to overcome the challenges described include, for example, the use of genetic algorithms [11] and fuzzy logic [17]. One potential approach to the control of a hybrid system is to use weather forecasts to help optimize the energy system's efficiency [18-20]. Under this approach, typically, wind forecast data are used to control the system, but icing, for example, is not considered although it can have a significant effect on performance especially in Arctic environments. According to Elistratov et al. [4], wind-diesel hybrid systems should consider the following design constraints:

- Limitations in equipment and fuel delivery due to the short periods in which transportation is possible;

- The need for quick installation and construction without the use of heavy lifting and transport equipment in the absence of roads;

- The possibility for maintenance without the involvement of qualified specialists.

Additionally, the hybrid system must have a high degree of automation, including adaptive algorithms and intelligent control, and a remote monitoring and diagnostic system to optimize expensive diesel fuel usage. 
Given the above, this study develops an existing field operating control system to improve its autonomous operation in Arctic conditions and maximize diesel fuel savings. It is shown that carbon-neutral technologies can be highly effective in Arctic zones subject to advanced control and reliable and safe operation. The study aims to identify how the system control approach affects system performance. Two control schemes are studied and compared with the use of a diesel engine only: 1. load following mode, and 2. cycle charge with short-term forecasting including icing effects. Additionally, a new wind turbine control method is proposed to decrease the effects of icing. The key novelties of the study are:

- The presentation of advanced control that includes climatic forecasting (wind speed, icing, etc.);

- The presentation of a new control approach to limit the effects of wind turbine icing.

The article is structured as follows. First, the hybrid system's control methods are explained. Next, the icing modeling and the novel pitch control approach are presented. In the Results section, before the discussion and conclusions, the effects of the different control methods are examined. This analysis is followed by the demonstration of the potential of a combined pitch and tip-to-speed ratio control approach to reduce the effects of icing.

\section{Materials and Methods}

This section presents the general layout of the proposed intelligent automatic control system (IACS) (Figure 1). Subsequently, the two parts of IACS, namely, standard control and advanced control, are explained in detail. This section also presents a novel turbine control scheme for reducing the effects of icing.

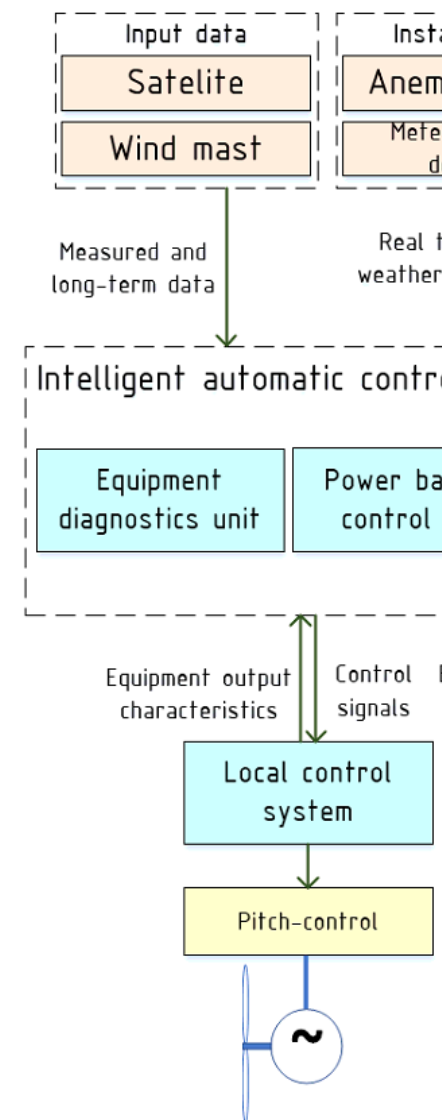

Wind turbine

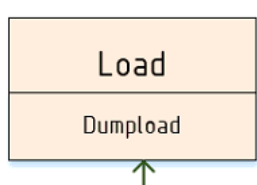

Local control system

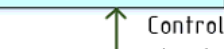

Load prediction unit

Advanced control

Icing prediction unit

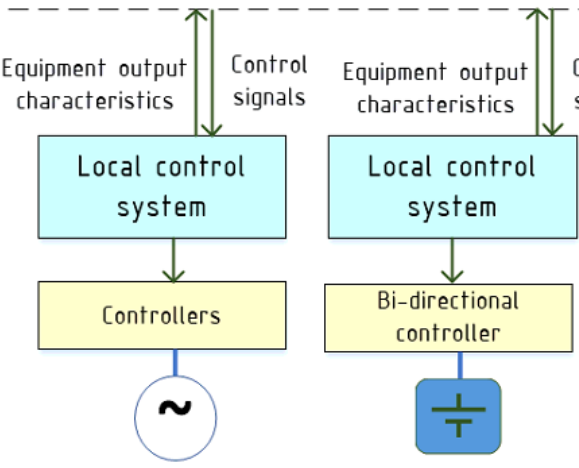

Diesel generators

\section{Storage system}

Figure 1. Functional diagram of IACS. 
To solve the challenges related to the hybrid energy system's fuel economy, a control methodology has been proposed by Elistratov et al. [21]. Their study argues that an intelligent automatic control system must [21]:

1. In real time, maximize the energy output of the wind power plant and fuel economy while covering the required load;

2. Provide remote monitoring of the hybrid system's parameters and operating modes;

3. Provide intelligent dispatching of the equipment, ensuring the maximum degree of autonomy;

4. Monitor the condition of the equipment, analyze the statistics of wind-diesel operating modes, and provide forecasting of the wind regime;

5. Ensure scheduling of equipment operation, maintenance, risk assessment, and emergency prevention interventions;

6. Duplicate the main controller of the system and the control and measuring systems; in an emergency, the possibility of manual control should be provided;

7. Be adaptable and supply energy around the clock, including in the event of a failure of the generating equipment.

Structurally, IACS consists of the following units, which are presented in Figure 1 and explained in the following two sub-sections:

- An equipment diagnostics unit (supervisory control and data acquisition of each system element);

- A power balance control unit that distributes energy between the system's generating equipment;

- A forecasting unit;

- An icing prediction unit.

The role of the first two units is to allow the system to achieve high renewable energy penetration. In contrast, the last two units compose an additional advanced control system that allows operation in harsh climatic conditions.

\subsection{Power Balance Control and Equipment Diagnostics Units (Standard Control)}

IACS is the software part of the "conversion, control and energy distribution" module of hybrid energy systems. This module provides the possibility of maximizing energy production from renewable energy sources due to the dynamic redistribution of power between the elements of the hybrid system and, as a result, minimizing fuel consumption with the option to disconnect the diesel generator entirely when renewable energy sources have sufficient capacity.

Figure 2 presents the hardware part of this module [22]. The hardware consists of two power devices for dynamic power balance control (i.e., the bi-directional current transducer and controlled dump load) and the main controller, both of which perform high-level control. The energy sources of the autonomous hybrid system are divided into two categories: leading and following sources.

Leading sources can be either the diesel component (as the main source, defining a supply voltage) or the bi-directional current transducer with connected batteries (in autonomous inverter mode) while the following sources adapt to the main source's voltage and generate power to the grid (e.g., the wind component).

If the capacity of the diesel and wind components, averaged over a certain period, exceeds the total power consumption, then to achieve the maximum use of renewable energy and thus to maximize diesel fuel economization, it is possible to turn off all diesel generators. In this case, the leading source becomes the bi-directional current transducer, which goes into standalone inverter mode and generates a network voltage. 


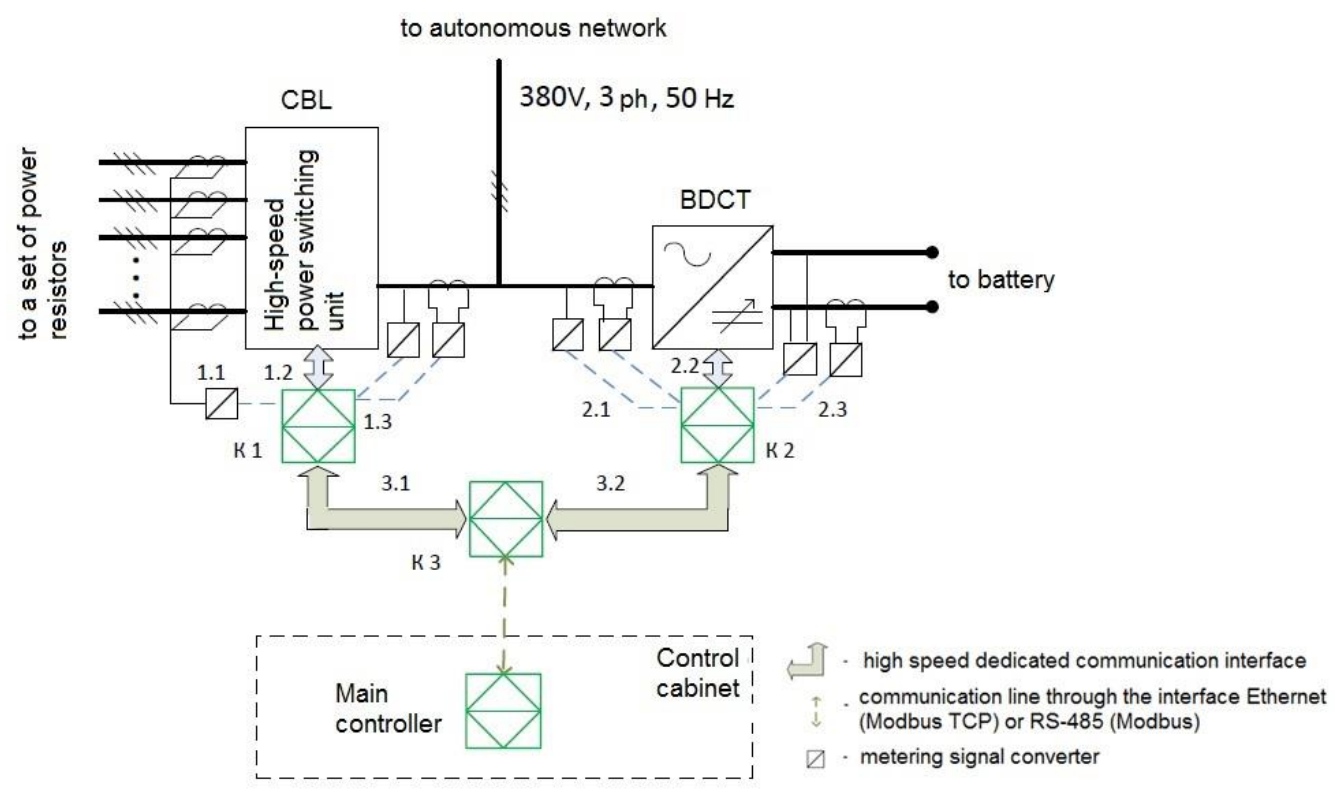

Figure 2. The "conversion, control and energy distribution" module of hybrid energy systems. K1: dump load controller; K3: common module controller; K2: bi-directional current transducer controller; 1.1: control stage current; 1.2: control circuits and internal power control circuits; 1.3: control and measurement of output electrical parameters; 2.1 : control and measurement of output electrical parameters; 2.2: control and management circuit of the internal power circuit of the bi-directional current transducer; 2.3: control and measurement of electrical parameters on the battery side.

\subsection{Forecasting and Icing Prediction Units (Advanced Control)}

The intermittent and fluctuating nature of wind energy production increases the importance of short-term weather forecasting in energy systems. With renewables being introduced into isolated power grids, the inherent uncertainty associated with weather forecasts places significant strain on existing off-grid power systems. These challenges lead to power quality and stability issues and affect both power grid management and balancing. Moreover, efficient system control requires accurate estimations of both energy supply and demand, which further highlights the importance of weather forecasting. In general, energy demand is more stable than renewable energy production, which is directly influenced by local weather systems. It is, however, important to acknowledge that unexpected peaks in demand can occur, for example, due to extreme weather. Poor weather predictions can lead to various problems in off-grid systems with detrimental economic and environmental effects. These challenges include the possibility of power shortages, the need for additional spinning or non-spinning reserves, and the increased use of diesel fuel. Another possible scenario is that the system can produce a large oversupply of energy, whereby diesel fuel will be burned needlessly. These considerations fully justify the need for high-quality weather predictions covering 10 to 60 -min time spans to ensure efficient grid supply and demand balancing [23].

Among traditional short-term forecasting methods such as the Auto-Regressive Integrated Moving Average (ARIMA), many modern processes use a form of deep learning known as recurrent neural networks (RNNs). A popular type of RNN, which is applied here, is the Long Short-Term Memory (LSTM) network. The models predicting wind characteristics and power output considered in this article are:

- Integrated autoregressive models (ARIMA) [24,25];

- Probabilistic models (Markov chain) [26,27];

- $\quad$ Statistical methods (GAMLSS);

- Machine learning (XGBoost, Random forest);

- Neural networks [28,29];

- Combined systems [30]. 
The ARIMA models are the most commonly used class of models for stationary signal forecasting (or a signal that can be made stationary). These models support random walk, seasonal trend, non-seasonal exponential smoothing, and autoregressive models.

Lags of the stationarized series in the forecasting equation are called "autoregressive" terms, while "moving average" terms describe the lags of the forecast errors. A time series, which needs to be differenced to be made stationary, is said to be an "integrated" version of a stationary series. Random-walk and random-trend models, autoregressive models, and exponential smoothing models are all considered special cases of ARIMA models.

The learning and encoding of signal temporal features are enabled by the RNN. This is an ideal approach to forecast signals, which are reasonably predictable based on past events. LSTM networks are recurrent networks that can overcome some of the historic challenges related to the training of recurrent networks, such as the vanishing gradients problem. This study will not go into the detail of evaluating and comparing forecasting models and will adopt the LSTM model due to its universally accepted ability to predict wind speed and load and perform predictive diagnostics of equipment condition.

Wind power plant output forecasts are based both on weather conditions and the power curves of the turbines. Moreover, at least one numerical weather forecast model should be integrated into the model being developed. These weather models will help to predict global weather patterns and their effects on local conditions. The numerical weather model (NWM) used to consider information other than data from local station observations is the NEMS4 model [31]. This model is provided free of charge by MeteoBlue (meteoblue AG, Basel, Switzerland) for a given date range and station. The data are provided in raw format.

The weather data prediction unit is connected to the icing prediction unit. When operating a wind turbine in a cold climate, additional power losses occur due to several types of icing: heavy frosting of the blades (in temperatures below $-25^{\circ} \mathrm{C}$ ), sedimentary (cloudy) icing, and atmospheric icing (Figure 3).

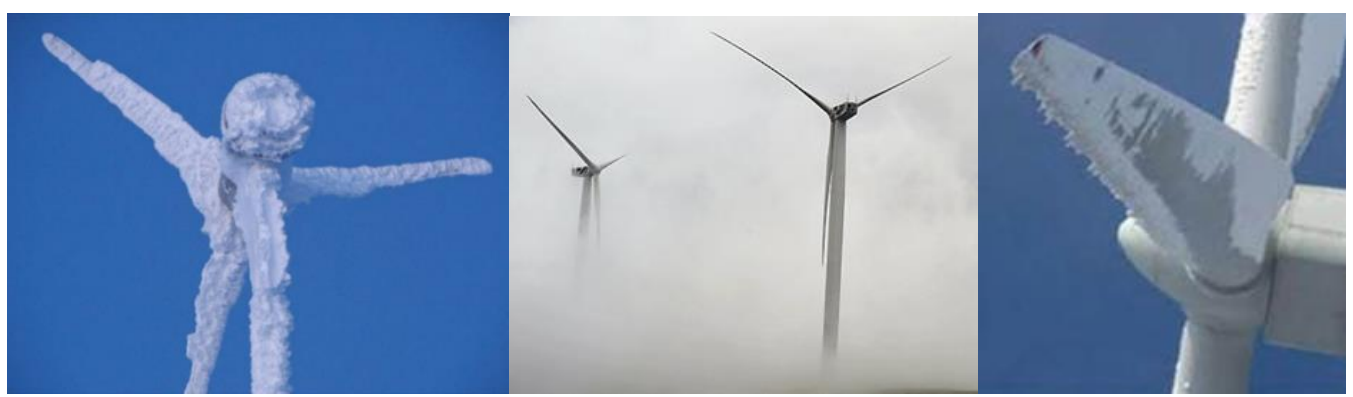

Figure 3. Types of icing [13].

Modern wind turbines include proven technical solutions to enable their operation in temperatures as low as $-35^{\circ} \mathrm{C}$ [32]. However, it is not only temperature that is important but also the duration of icing. For areas with long winter seasons, it is important to strengthen the control system by adding an icing prediction unit. This will make it possible to effectively use the existing systems to protect against ice, which can grow intensively on the surface of the blades.

According to the Makkonen theory [33], the functionality of the icing intensity indicator depends on the predicted weather parameters. Based on these calculations, a decision is made to turn on the protection system. The intensity of icing is determined by the following equation:

$$
\mathrm{I}=\alpha \times \beta \times \gamma \times \mathrm{LWC} \times \mathrm{v} \times \mathrm{A},
$$

where $\alpha$ is the collision efficiency factor; $\beta$ is the coefficient of sticking efficiency; $\gamma$ is the coefficient of efficiency of growth (accretion); LWC is the liquid water content in the air (mass particle concentration), $\mathrm{kg} / \mathrm{m}^{3} ; \mathrm{v}$ is the speed of incoming airflow (particle 
velocity), m/s; A is the cross-sectional area of the wind turbine blade (relative to the direction of the airflow velocity vector), $\mathrm{m}^{2}$. LWC values and alpha coefficients depend on the weather parameters (pressure, temperature, humidity, specific water content in the environment, etc.). In this article, the prediction of the onset of atmospheric icing is based on the occurrence of the conditions presented in Table 1.

Table 1. Conditions for atmospheric icing (adopted from [34]).

\begin{tabular}{cc}
\hline Parameter & Condition \\
\hline Wind Speed & $>3 \mathrm{~m} / \mathrm{s}$ \\
Temperature & $-4{ }^{\circ} \mathrm{C}>\mathrm{T}>-20{ }^{\circ} \mathrm{C}$ \\
Relative Humidity & $>95 \%$ \\
\hline
\end{tabular}

To protect the blades from ice, special anti-icing and de-icing systems are used, as described in detail in [32,35]. In the icing prediction unit, the input data are acquired from meteorological instruments (weather data), wind measuring systems (wind speed, data correlation for the "heated-unheated anemometer" system), and directly from the wind turbine (power). When the output power from the wind turbine drops and there are conditions for atmospheric icing (Table 1), the system produces a signal to turn on the anti-icing system.

All icing protection systems are divided into two types: active and passive. Active systems require additional power from their own system (these include all anti-icing systems installed inside or outside the blade). Passive systems do not incur additional costs when operating the wind turbine (de-icing systems, for example, painting the blades in black). The pitch-control system for wind turbines with a capacity of more than $1 \mathrm{MW}$ is categorized as a passive system since it is preinstalled and does not incur substantial additional costs to be operated. However, for wind turbines of a maximum $1 \mathrm{MW}$ capacity, a feasibility study concerning the application of the regulation system is required.

In the case of a pitch-control in a lower capacity turbine, it is necessary to compare cost and effectiveness. The possible effect can be estimated based on the power output increase. Figure 4 shows how the turbine power coefficient changes due to icing based on the airfoil data reported by Homola et al. [36]. The calculations are based on Wilson's equation [37] and involve different angles of attack and tip-to-speed ratios. It is noticeable that, when icing occurs, the changes in the ratio of the lift and drag forces influence performance but so do changes in the tip-to-speed ratio.

In the development of a pitch-control-based approach, optimal drag-to-lift ratios from several references including airfoil performance data for both clean and icing conditions [32,33,35-39] are used. The data used include several wind speeds, as seen in Table 2. Wilson's equation [37] with different angles of attack and tip-to-speed ratios is used to predict the maximum power coefficient of a wind turbine. The results under four conditions are presented: 1 . clean turbine, 2. turbine under icing conditions, 3 . turbine under icing conditions with pitch control, and 4. turbine under icing conditions with combined pitch and tip-to-speed ratio control. The results for different wind speeds are summarized in Table 2. This analysis reveals that the pitch control can overcome some of the icing effects, but the combined pitch and tip-to-speed ratio control has even higher loss reduction potential. Therefore, the potential of the combined pitch and tip-to-speed ratio control is examined more closely in the following section. 


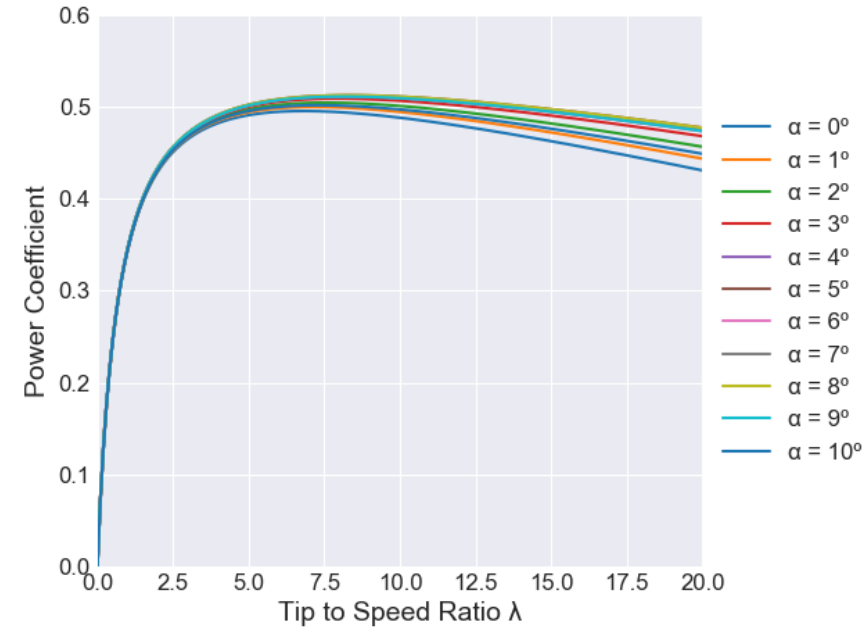

(a)

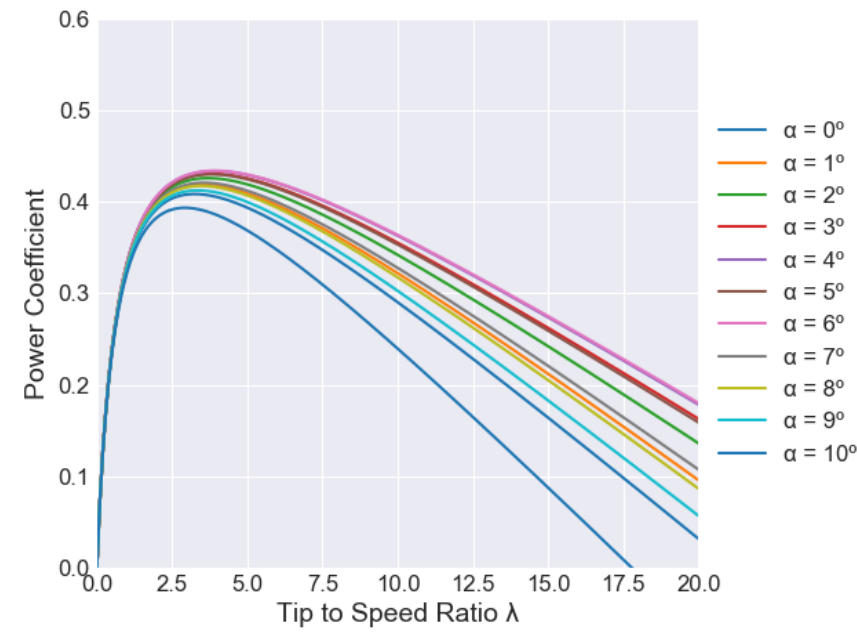

(b)

Figure 4. Effects of tip-to-speed ratio and angle of attack on turbine power coefficient for (a) clean turbine and (b) during icing based on the drag to lift data (adopted from [34]).

Table 2. Results summary of the performance analysis for a wind turbine with and without icing (adopted from [34]). The results are presented for a clean turbine ( $\left.\mathrm{C} \mathrm{p}_{\text {clean }}\right)$, a turbine under icing conditions ( $\left.\mathrm{C} \mathrm{p}_{\text {icing }}\right)$, a turbine under icing conditions with pitch control $\left(\mathrm{C} \mathrm{p}_{\alpha}\right)$, and a turbine under icing conditions with pitch and tip-to-speed ratio control $\left(\mathrm{C}_{\alpha \lambda}\right)$.

\begin{tabular}{ccccccccc}
\hline Wind Speed $(\mathbf{m} / \mathbf{s})$ & $\mathbf{C p}_{\text {clean }}$ & $\boldsymbol{\lambda}$ & $\boldsymbol{\alpha}\left({ }^{\circ}\right)$ & $\mathbf{C p}_{\text {icing }}$ & $\mathbf{C p}_{\boldsymbol{\alpha} \boldsymbol{\lambda}}$ & $\boldsymbol{\lambda}_{\text {opt }}$ & $\mathbf{C p}_{\boldsymbol{\alpha}}$ & $\boldsymbol{\alpha}_{\text {opt }}\left({ }^{\circ}\right)$ \\
\hline 2.2 & 0.4755 & 5.6 & 5 & 0.4157 & 0.4526 & 4.6 & 0.4499 & 0 \\
3.2 & 0.4565 & 4.7 & 4 & 0.3495 & 0.3848 & 2.8 & 0.3597 & 9 \\
6 & 0.5126 & 8.3 & 5 & 0.3821 & 0.4340 & 3.9 & 0.3907 & 6 \\
7.3 & 0.4984 & 7.0 & 6 & 0.3461 & 0.4078 & 3.2 & 0.3564 & 5 \\
19.2 & 0.4173 & 3.5 & 2 & 0.3829 & 0.4002 & 3.1 & 0.3989 & 5 \\
\hline
\end{tabular}

\section{Results}

This section presents the results of two hybrid system control modes and compares their performance with that of the diesel-only system. The data are presented for a conventional load following mode based on field data and for a simulated IACS operating mode. Additionally, the potential of the combined pitch and tip-to-speed ratio control approach is demonstrated, and the turbine icing modeling approach is verified.

\subsection{Hybrid System Modes}

A comparative analysis of the operating modes of an existing Arctic wind-diesel hybrid system was carried out to assess the practical benefits of the implementation of intelligent control algorithms. The correlation between the structure of the considered equipment and high renewable energy penetration is illustrated in Figure 5. 


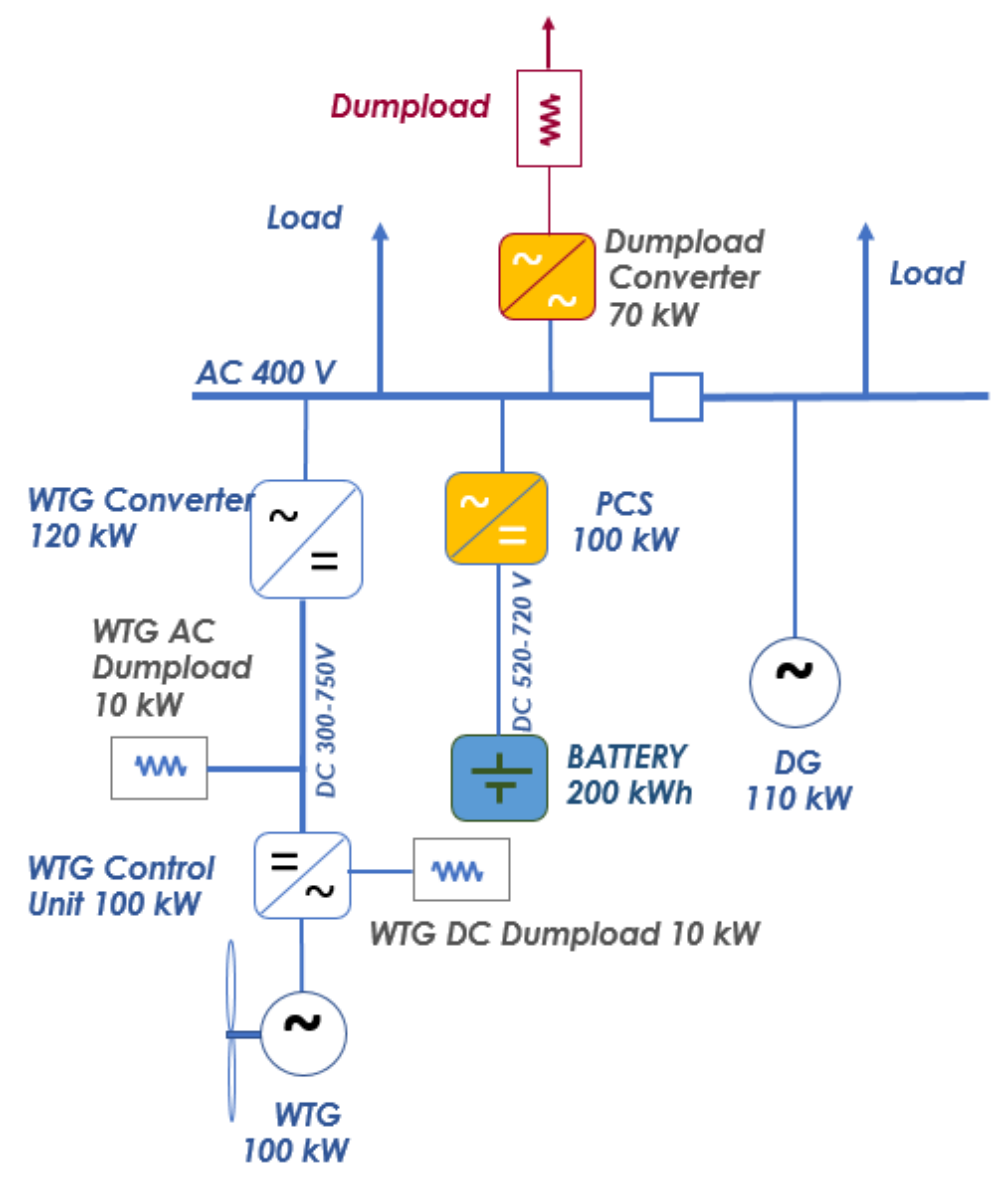

Figure 5. Structural scheme of the wind-diesel hybrid system.

The model used is compiled in Python (Python Software Foundation, Gemini Dr., Beaverton, OR, USA), on the core of a real wind-diesel power plant (WDPP) control system. The system has the following properties: a wind turbine of $100 \mathrm{~kW}$, a full capacity converter, a diesel generator set of $110 \mathrm{~kW}$, a battery energy storage system with a capacity of $200 \mathrm{kWh}$, a dump load with a capacity of $70 \mathrm{~kW}$, and a real load graph (max $55 \mathrm{~kW}$ ). The limitations of the model are as follows. Firstly, loading the initial data does not take into account the delay in their download. Secondly, the authors do not investigate the influence of the model operation speed on the signals of real facilities.

(1) Load following mode: In this mode, the diesel generator outputs electricity in accordance with the load (leading mode). The surplus electricity is first used to charge the battery and then to heat the water using the dump load. Disconnection of the diesel component is possible in the case of a fully charged battery and a prolonged excess of wind turbine output over the load. The diesel component is switched on when the battery voltage reaches the specified minimum. Thus, the battery works in deep cycles during periods of high winds. The dump load, together with the battery, contributes to the regulation of the network voltage to achieve its stable operation and acts as a buffer for load hesitation. Surplus energy is utilized in the form of useful heat for heating needs. Figure 6 shows hourly balances of power in supervisory control and data acquisition (SCADA)-based monitoring data over five days. From the figure, it is noticeable that for the majority of the time when the wind turbine is operating, the power balance significantly exceeds the load.

(2) Cycle charge with short-term forecasting mode: In this mode, the diesel generator works as an additional source of energy to cover power shortages. In the case of favorable wind turbine output forecasts, it is switched off. At the same time, the battery is used more efficiently and the size of the buffer capacity of the dump load 
is reduced. The changes in dump load performance are visible when comparing Figures 6 and 7. From Figure 7, it can be seen that the diesel generator is repeatedly replaced by the battery discharge.

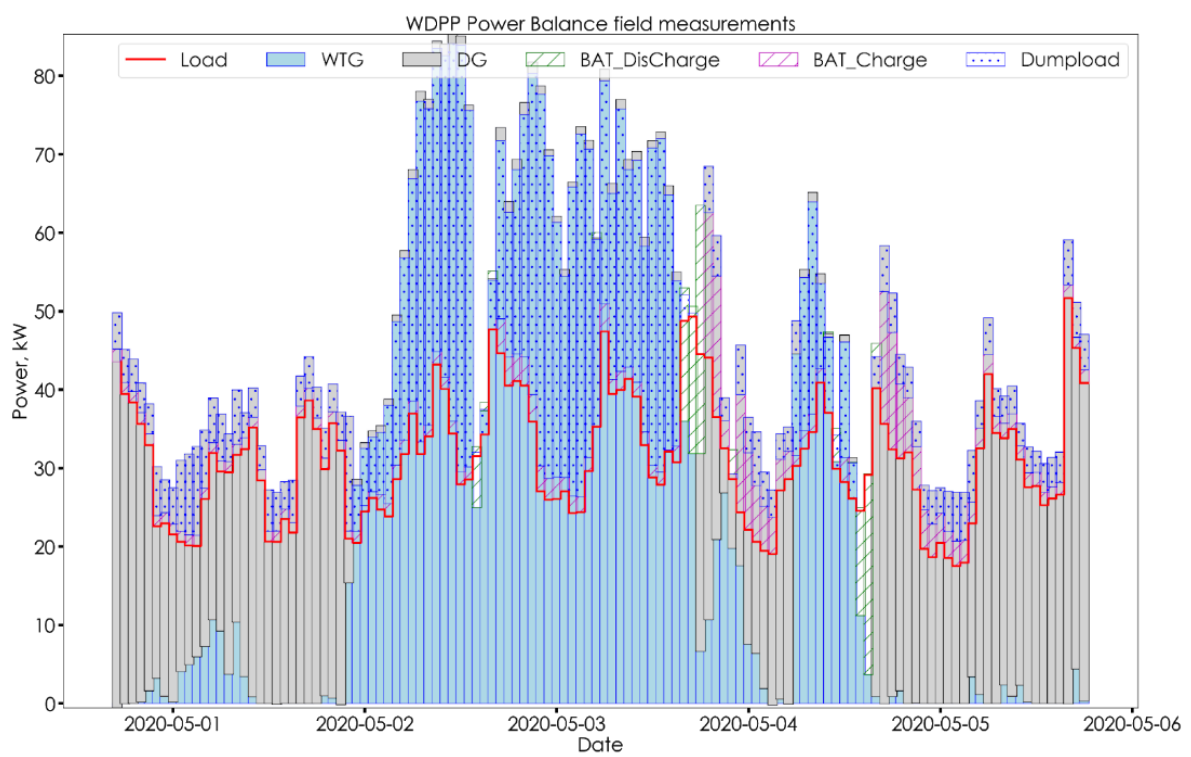

Figure 6. Power balance under the load following mode (SCADA measurements).

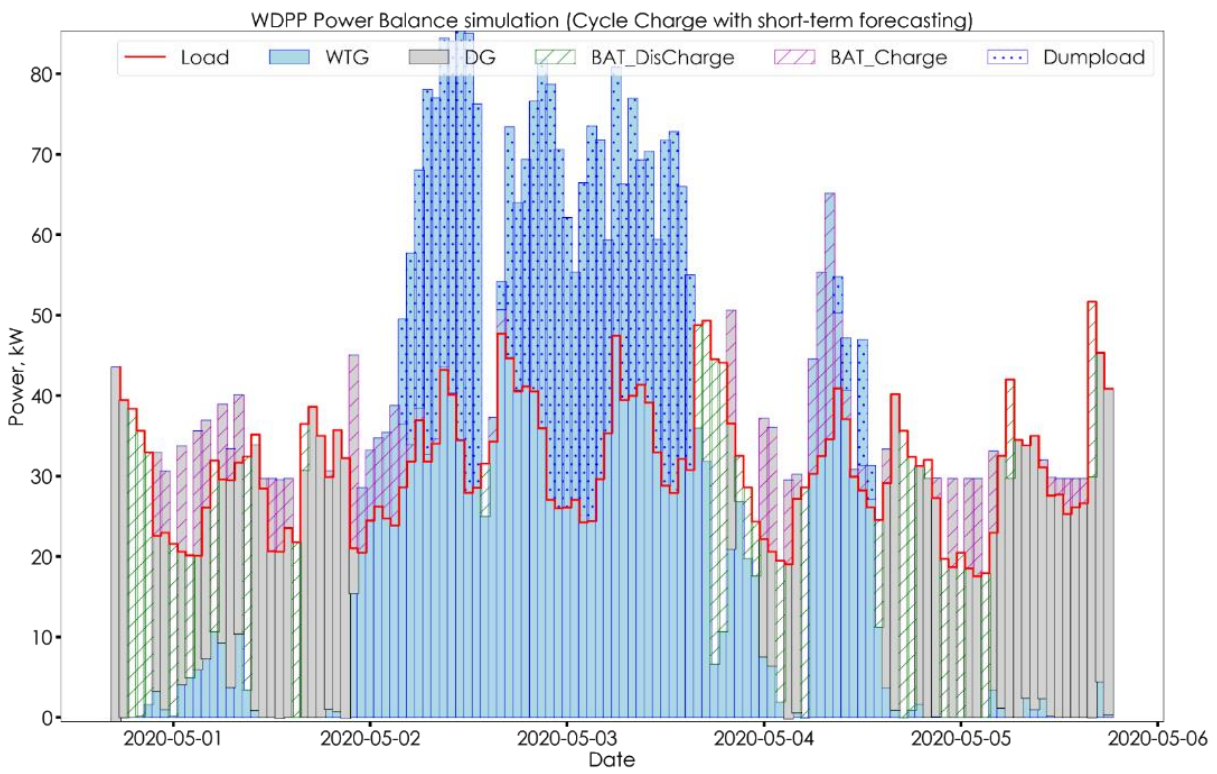

Figure 7. Power balance under the cycle charge and short-term forecasting mode (simulation).

A more detailed comparison of the results is summarized in Table 3. The integration of the wind turbine and battery into the system during the analysis period facilitated fuel savings of $38 \%$; however, to ensure the stable operation of the power system, a significant portion of the electricity generated by the wind turbine $(48 \%)$ was distributed to the secondary regulatory load. With the wind turbine production forecasts and battery operation functioning in a cyclic mode, the share of wind turbine energy going to the secondary control load decreased to $38 \%$ and renewable energy penetration increased to $60 \%$. At the same time, the number of battery cycles increased 2.2 times, up to two cycles of $80 \%$ charge/discharge per day (660 cycles per year). In their research employing similar system components (diesel generator, wind turbine, and battery), Elkadeem et al. [5] were 
able to reduce diesel fuel consumption by $85 \%$ (compared with a diesel-only system); however, their study had a significantly larger relative share of wind power capacity than the current study (more than two times the diesel generators' power). When compared with the load following mode, doubling the share of wind turbines seems to also roughly double the fuel savings. In relative terms, Li et al. [6] employed approximately similar diesel generator and wind power capacities but had significantly higher battery capacity (roughly three times higher). Their study reports a fuel saving of $74 \%$. This leads to the conclusion that the proposed cycle charge with short-term forecasting mode can offer fuel-saving benefits by adding significantly more wind power or battery capacity without adding any actual new capacity.

Table 3. Operation statistics over five days.

\begin{tabular}{cccc}
\hline Parameter & $\begin{array}{c}\text { Diesel Only } \\
\text { (Simulation) }\end{array}$ & $\begin{array}{c}\text { WDDP Load Following } \\
\text { Mode (Field) }\end{array}$ & $\begin{array}{c}\text { WDPP Cycle Charge with } \\
\text { Short-Term Forecasting } \\
\text { Mode (Simulation) }\end{array}$ \\
\hline DG energy output, $\mathrm{kWh}$ & 3804 & 2423 & 1591.0 \\
WTG energy output, kWh & 0 & 3302 & 3302 \\
Battery roundtrip output, kWh & 0 & 450 & 937 \\
Battery 80\%, DOD cycles & 0 & 4 & 9 \\
DG start/stop cycles & 1 & 3 & 13 \\
DG specific fuel consumption, g/kWh & 313 & 304 & 302 \\
Fuel consumption, liters & 1417 & 876 & 573 \\
DG average load, $\%$ & 31.5 & 35 & 31.5 \\
Fuel savings, 1 & 0 & $540(38 \%)$ & $844(60 \%)$ \\
Dump load Energy consumption, $\mathrm{kWh}$ & 0 & 1598 & 1247 \\
\hline
\end{tabular}

\subsection{The Effect of Pitch and Tip-to-Speed Ratio Control}

To verify the chosen wind turbine icing modeling approach, the performance values of Table 2 were used to build power curves for clean and icing cases. The results of the modeling were then compared with the predictions from the Finnish Icing Atlas, which is based on the Finnish Wind Atlas [39] and ice aggregation modeling according to standard ISO 12394:2001. Since the figures in the Finnish Icing Atlas are reasonably sensitive to location, an area with a radius of $30 \mathrm{~km}$ was used to determine the maximum production loss values in each area for comparison with the exact location values presented in parentheses to illustrate local variations. The comparison reveals that the model presented in this work generally overestimates losses (Table 4). The magnitude of the predicted losses is, however, still similar to those achieved. This indicates that the proposed model can produce reasonable estimates for icing effects even though it is based on single airfoil data rather than data for full turbine blade shapes.

Table 4. Icing model comparison between the developed model and the Finnish Icing Atlas.

\begin{tabular}{ccccc}
\hline Location & Latitude & Longitude & Production Loss (\%) & $\begin{array}{c}\text { Icing Atlas Production } \\
\text { Loss (\%) }\end{array}$ \\
\hline Olhava & $65^{\circ} \mathrm{N}$ & $25^{\circ} \mathrm{E}$ & 7.1 & $5.9(4.6)$ \\
Madetkoski & $68^{\circ} \mathrm{N}$ & $27^{\circ} \mathrm{E}$ & 12.4 & $9.3(4.0)$ \\
Jääräjoki & $70^{\circ} \mathrm{N}$ & $28^{\circ} \mathrm{E}$ & 6.3 & $8.4(1.5)$ \\
\hline
\end{tabular}

To implement the developed models in the energy system modeling tool, three curve fits were built based on the Madetkoski data from Finland. Figure 8 presents the power curves for a clean case, icing case, and pitch and tip-to-speed (optimized) control case and illustrates how the applied control approach can affect turbine performance. The total positive effect of optimized control on turbine power below the nominal operating point is between $2 \%$ to $5 \%$. For wind turbines of medium and high capacity in Arctic zones, the optimized control system is advisable since the total cost of its installation is less than the 
total economic savings it can achieve. However, for wind turbines with a capacity of less than $300 \mathrm{~kW}$, the installation of such a system must be confirmed by the relevant technical and economic analyses.

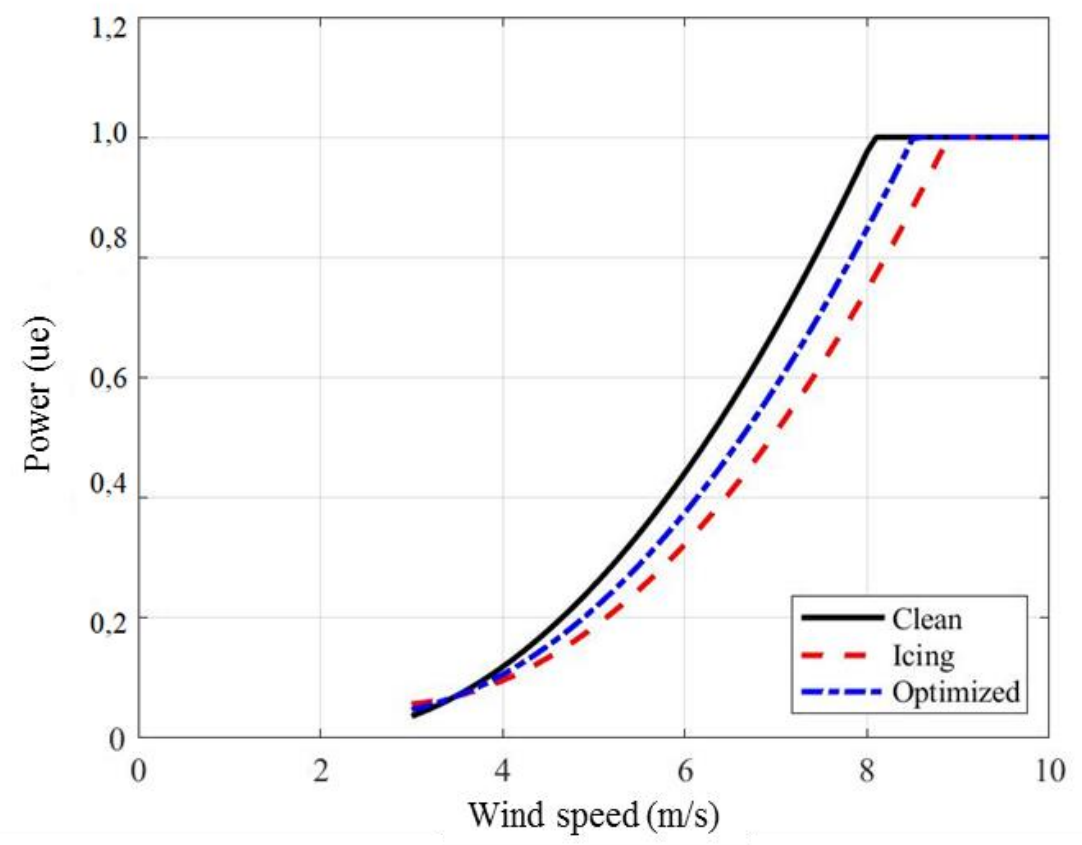

Figure 8. Wind turbine power curve under clean, icing, and optimized conditions.

\section{Conclusions}

1. The article presents the architecture of an advanced intelligent automatic control system for a wind-diesel hybrid system with high renewable energy penetration and describes the main modes of its operation.

2. The integration of the wind turbine and battery into the hybrid system enabled fuel savings of $38 \%$, which were achieved by replacing the power generated by the diesel engine with wide turbine and battery power. In the load following mode, it was possible to disconnect the diesel generator when the battery was fully charged and wind turbine production was high. The dump load and the battery were used to regulate the network voltage. The excess electricity produced was used for heating.

3. With the addition of wind speed forecasting (LSTM model) and the cyclic charge mode, the share of wind turbine energy going to the secondary dump load decreased to $38 \%$, and diesel fuel savings increased to $60 \%$. Overall, the fuel savings correspond to the effects of significant additions of either wind turbine or battery capacities.

4. The net savings of using pitch and tip-to-speed ratio control exceed the cost of installing this system for medium- and high-capacity wind turbines. The use of the icing prediction unit in conjunction with weather forecasting and the turbine control system provides a more reliable operation of the wind turbine in harsh climatic conditions. It is estimated that these systems can reduce the operational expenditure (OPEX) by approximately $20 \%$.

It is worth noting that the article does not examine the diagnostic unit. The current trend is the "complication" of data analytics towards deep machine learning and predictive diagnostics to prevent accidents through the application of accumulated experience and the analysis of large amounts of data.

The article considers the example of the onset of atmospheric icing; however, in the icing prediction block, it is necessary to calculate icing intensity using formula (1). In future research, these indicators will be studied in greater detail. 
Author Contributions: The article is the result of the efforts of two working groups, one in St. Petersburg (SPbPU, Russia) and one in Lappeenranta (LUT University, Finland). Conceptualization, supervision, and project administration were overseen by V.E. and T.T.-S.; methodology, IACSarchitecture, and visualization were overseen by R.D.; modeling and validation hybrid system modes were overseen by M.K.; modeling and validation of the pitch control system were overseen by A.J.L. and A.G.; formal analysis, investigation, and formalization of results were overseen by I.B. All authors have read and agreed to the published version of the manuscript.

Funding: The research was carried out as part of the World-Class Research Center Program: Advanced Digital Technologies (contract No. 075-15-2020-934 dated 17.11.2020) and supported by the ENI CBC project KS1054, "Energy-efficient systems based on renewable energy for Arctic conditions".

Data Availability Statement: Nature data were gathered from the SCADA hybrid system project in Russian Arctic areas. Data for the icing calculations were collected from the Finnish Icing Atlas (Tammelin et al., 2011) and ice aggregation modeling according to standard ISO 12394:2001.

Conflicts of Interest: The authors declare no conflict of interest. The funders had no role in the design of the study, the collection, analysis, or interpretation of data, the writing of the manuscript, or the decision to publish the results.

\section{References}

1. Elistratov, V. Energy supply of autonomous territories based on renewable energy sources. In Proceedings of the 7th International Conference on Energy Efficiency and Agricultural Engineering, EE and AE 2020, Ruse, Bulgaria, 12-14 November 2020.

2. IEA. Projected Costs of Generating Electricity. 2020. Available online: https://www.iea.org/reports/projected-costs-ofgenerating-electricity-2020 (accessed on 30 April 2021).

3. Kazem, H.A.; Al-Badi, H.A.S.; Al Busaidi, A.S.; Chaichan, M.T. Optimum design and evaluation of hybrid solar/wind/diesel power system for Masirah Island. Environ. Dev. Sustain. 2017, 19, 1761-1778. [CrossRef]

4. Elistratov, V.; Kudryasheva, I.; Pilipets, P. Energy efficient solutions of power supply in north regions. Appl. Mech. Mater. 2015, 725, 559-568. [CrossRef]

5. Elkadeem, M.R.; Wang, S.; Sharshir, S.W.; Atia, E.G. Feasibility analysis and techno-economic design of grid-isolated hybrid renewable energy system for electrification of agriculture and irrigation area: A case study in Dongola, Sudan. Energy Convers. Manag. 2019, 196, 1453-1478. [CrossRef]

6. Li, C.; Zhou, D.; Wang, H.; Lu, Y.; Li, D. Techno-economic performance study of stand-alone wind/diesel/battery hybrid system with different battery technologies in the cold region of China. Energy 2020, 192, 116702. [CrossRef]

7. Elistratov, V.; Konischev, M.; Fedorov, M. Optimization of power supply of the circumpolar territories on the basis of renewable energy sources. In Proceedings of the International Conference on Industrial Engineering, Applications and Manufacturing, ICIEAM 2017, St. Petersburg, Russia, 16-19 May 2017.

8. Ansari, M.M.T.; Velusami, S. DMLHFLC (Dual mode linguistic hedge fuzzy logic controller) for an isolated wind-diesel hybrid power system with BES (battery energy storage) unit. Energy 2010, 35, 3827-3837. [CrossRef]

9. Vachirasricirikul, S.; Ngamroo, I.; Kaitwanidvilai, S. Coordinated SVC and AVR for robust voltage control in a hybrid wind-diesel system. Energy Convers. Manag. 2010, 51, 2383-2393. [CrossRef]

10. Elistratov, V.V.; Denisov, R.S. The optimization of hybrid systems' operating modes based on renewable energy. In Proceedings of the XVI-th International Conference on Electrical Machines, Drives and Power Systems ELMA 2019, Varna, Bulgaria, 6-8 June 2019.

11. Turkia, V.; Huttunen, S.; Thomas, W. Method for Estimating Wind Turbine Production Losses Due to Icing; VTT Technical Research Centre of Finland: Espo, Finland, 2013.

12. Wei, K.; Yang, Y.; Zuo, H.; Zhong, D. A review on ice detection technology and ice eliminationtechnology for wind turbine. Wind Energy 2020, 23, 433-457. [CrossRef]

13. Thompson, G.; Nygaard, B.E.; Makkonen, L.; Dierer, S. using the weather research and forecasting (wrf) model to predict ground/structural icing. In Proceedings of the IWAIS XIII, Andermatt, Switzerland, 8-11 September 2009.

14. Etemaddar, M.; Hansen, M.O.; Moan, T. Wind turbine aerodynamic response under atmospheric icing conditions. Wind Energy 2012, 17, 241-265. [CrossRef]

15. Bhatti, T.S.; Al-Ademi, A.A.F.; Bansal, N.K. Load-frequency control of isolated wind-diesel-microhydro hybrid power systems (WDMHPS). Energy 1997, 22, 461-470. [CrossRef]

16. Mi, Y.; Song, Y.; Fu, F.; Wang, S. The adaptive sliding mode reactive power control strategy for wind-diesel power system based on sliding mode observer. IEEE Trans. Sustain. Energy 2020, 11, 2241-2251. [CrossRef]

17. Mahto, T.; Mukherjee, V. A novel scaling factor based fuzzy logic controller for frequency control of an isolated hybrid power system. Energy 2017, 130, 339-350. [CrossRef]

18. Zavala, V.M.; Constantinescu, E.M.; Krause, T.; Anitescu, M. On-line economic optimization of energy systems using weather forecast information. J. Process Control 2009, 19, 1725-1736. [CrossRef] 
19. Zhang, W.; Maleki, A.; Rosen, M.A.; Liu, J. Sizing a stand-alone solar-wind-hydrogen energy system using weatherforecasting and a hybrid search optimization algorithm. Energy Convers. Manag. 2010, 180, 609-621. [CrossRef]

20. Romero, A.; Carvalho, M.; Millar, D.L. Optimal design and control of wind-diesel hybrid energy systems for remote arctic mines. J. Energy Resour. Technol. 2016, 138, 062004. [CrossRef]

21. Elistratov, V.V.; Panfilov, A.A.; Konyschev, M.A.; Denisov, R.S. The application of adapted materials and technologies to create energy systems based on renewable energy sources under harsh climatic conditions. Appl. Solar Energy 2018, 54, 472-476. [CrossRef]

22. Elistratov, V.V.; Denisov, R.S. Energetic and ecological justification of RE-hybrid systems for vulnerable ecosystems. In IOP Conference Series: Earth and Environmental Science; IOP Publishing: Bristol, UK, 2021; Volume 689.

23. Elistratov, V.V.; Bogun, I.V.; Kasina, V.I. Optimization of wind-diesel power plants parameters and placement for power supply of russia's northern regions consumers. In Proceedings of the 16th Conference on Electrical Machines, Drives and Power Systems, ELMA 2019, Varna, Bulgaria, 6-8 June 2019.

24. Shukur, O.B.; Lee, M.H. Daily wind speed forecasting through hybrid KF-ANN model based on ARIMA. Renew.Energy 2015, 76, 637-647. [CrossRef]

25. Singh, S.N.; Mohapatra, A. Repeated wavelet transform based ARIMA model for very short-term wind speed forecasting. Renew. Energy 2019, 136, 758-768.

26. Carpinone, A.; Giorgio, M.; Langella, R.; Testa, A. Markov chain modeling for very-short-term wind power forecasting. Electr. Power Syst. Res. 2015, 122, 152-158. [CrossRef]

27. D'Amico, G.; Masala, G.; Petroni, F.; Sobolewski, R.A. Managing wind power generation via indexed semi-markov model and copula. Energies 2020, 13, 4246. [CrossRef]

28. Marugán, A.P.; Márquez, F.P.G.; Perez, J.M.P.; Ruiz-Hernández, D. A survey of artificial neural network in wind energy systems. Appl. Energy 2018, 228, 1822-1836. [CrossRef]

29. Santhosh, M.; Venkaiah, C.; Kumar, D.V. Ensemble empirical mode decomposition based adaptive wavelet neural network method for wind speed prediction. Energy Convers. Manag. 2018, 168, 482-493. [CrossRef]

30. Huang, C.-Y.; Liu, Y.-W.; Tzeng, W.-C.; Wang, P.-Y. Short term wind speed predictions by using the grey prediction model based forecast method. IEEE Green Technol. Conf. 2011, 1-5. [CrossRef]

31. Gobiet, A.; Mitterer, C.; Jöbst, L.; Steinkogler, W.; Rieder, H.; Olefs, M.; Studeregger, A.; Monti, F.; Bellaire, S. Operational forecasting of wet snow avalanche activity: A case study for the eastern European Alps. In Proceedings of the International Snow Science Workshop, Breckenridge, CO, USA, 3-7 October 2016; Proceedings ISSW: Breckenridge, CO, USA, 2016 ; pp. 132-139.

32. Battisti, L. Wind turbines in cold climates: Icing impacts and mitigation systems. In Green Energy and Technology; Springer: New York, NY, USA, 2015.

33. Parent, O.; Ilinca, A. Anti-icing and de-icing techniques for wind turbines: Critical review. Cold Reg. Sci. Technol. 2011, 65, 88-96. [CrossRef]

34. Lugo, A.J. Pitch Control System for a Specific Arctic Wind Turbine. Master's Thesis, Lappeenranta University of Technology LUT, Lappeenranta, Finland. Available online: https:/ /lutpub.lut.fi/bitstream/handle/10024/161310/AfonsoLugo_2020 _MasterThesis_PitchControlSystem.pdf?isAllowed=y\&sequence=1 (accessed on 30 April 2021).

35. Gantasala, S.; Tabatabaei, N.; Cervantes, M.; Aidanpää, J.-O. Numerical investigation of the aeroelastic behavior of a wind turbine with iced blades. Energies 2019, 12, 2422. [CrossRef]

36. Homola, M.C.; Virk, M.S.; Wallenius, T.; Nicklasson, P.J.; Sundsbø, P.A. Effect of atmospheric temperature and droplet size variation on ice accretion of wind turbine blades. J. Wind Eng. 2010. [CrossRef]

37. Wilson, R.E.; Lissaman, P.B.; Walker, S.N. Aerodynamic Performance of Wind Turbines; Energy Research and Development Administration, Technical Information Center; Oregon State University: Corvallis, OR, USA, 1976.

38. Hudecz, A. Icing Problems of Wind Turbine Blades in Cold Climates. Ph.D. Thesis, Technical University of Denmark, Copenhagen, Denmark. Available online: https:/ / orbit.dtu.dk/en/publications/icing-problems-of-wind-turbine-blades-in-cold-climates (accessed on 30 April 2021).

39. Tammelin, B.; Vihma, T.; Atlaskin, E.; Badger, J.; Fortelius, C.; Gregow, H.; Horttanainen, M.; Hyvönen, R.; Kilpinen, J.; Latikka, J.; et al. Production of the Finnish wind atlas. Wind Energy 2013. [CrossRef] 